\title{
Association between lipid accumulation and the cannabinoid system in Huh7 cells expressing HCV genes
}

\author{
MAKO TOYODA $^{1}$, AKIRA KITAOKA ${ }^{1}$, KAZUYUKI MACHIDA ${ }^{1}$, TAKUYA NISHINAKAGAWA $^{1}$, RYOKO YADA $^{3}$, \\ MOTOYUKI KOHJIMA ${ }^{4}$, MASAKI KATO ${ }^{5}$, KAZUHIRO KOTOH ${ }^{5}$, NAOYA SAKAMOTO ${ }^{6}$, GOSHI SHIOTA ${ }^{7}$, \\ MAKOTO NAKAMUTA $^{3,4}$, MANABU NAKASHIMA ${ }^{1}$ and MUNECHIKA ENJOJI ${ }^{1,2,3}$ \\ ${ }^{1}$ Department of Clinical Pharmacology, Faculty of Pharmaceutical Sciences and ${ }^{2}$ Health Care Center Clinic, \\ Fukuoka University, Fukuoka; ${ }^{3}$ Clinical Research Center and ${ }^{4}$ Department of Gastroenterology, Kyushu \\ Medical Center, National Hospital Organization, Fukuoka; ${ }^{5}$ Department of Medicine and Bioregulatory \\ Science, Graduate School of Medical Sciences, Kyushu University, Fukuoka; ${ }^{6}$ Department of \\ Gastroenterology and Hepatology, Tokyo Medical and Dental University, Tokyo; ${ }^{7}$ Division of \\ Molecular and Genetic Medicine, Department of Genetic Medicine and Regenerative \\ Therapeutics, Graduate School of Medicine, Tottori University, Yonago, Japan
}

Received December 14, 2010; Accepted January 28, 2011

DOI: $10.3892 /$ ijmm.2011.622

\begin{abstract}
Evidence from clinical and laboratory studies has accumulated indicating that the activation of the cannabinoid system is crucial for steatosis, especially in non-alcoholic fatty liver disease. However, the association between hepatitis $\mathrm{C}$ virus $(\mathrm{HCV})$ infection and the cannabinoid system has not been well investigated and it is unclear whether steatosis in chronic hepatitis $\mathrm{C}$ develops via activation of the endocannabinoid/cannabinoid receptor signaling pathway. In this study, we examined the expression of a cannabinoid receptor (CB1) and the lipid accumulation in the hepatic Huh7 cell line, expressing HCV genes. We utilized Huh7/Rep-Feo-1b cells stably expressing HCV non-structural proteins (NS) 3, NS4, NS5A, and NS5B, as well as Tet-On Core-2 cells, in which the $\mathrm{HCV}$ core protein expression is inducible. Significantly higher levels of stored triglycerides were found in Huh7/Rep-Feo-1b cells compared to Huh7 cells. Also, triglyceride accumulation and $\mathrm{CB} 1$ receptor expression were down-regulated in Huh7/ Rep-Feo-1b cells after HCV reduction by IFN $\alpha$. Moreover,
\end{abstract}

Correspondence to: Dr Munechika Enjoji, Health Care Center, Fukuoka University, 8-19-1 Nanakuma, Jonan-ku, Fukuoka 814-0180, Japan

E-mail: enjoji@adm.fukuoka-u.ac.jp

Abbreviations: 2-AG, 2-arachidonoylglycerol; $\mathrm{CH}-\mathrm{C}$, chronic hepatitis C; FAAH, fatty-acid amide hydrolase; FASN, fatty acid synthase; MTTP, microsomal triglyceride transfer protein; NAFLD, non-alcoholic fatty liver disease; NASH, non-alcoholic steatohepatitis; PBS, phosphate buffered saline; ROS, reactive oxygen species; SREBP-1c, sterol regulatory element-binding protein 1c; VLDL, very low-density lipoprotein

Key words: cannabinoid, cannabinoid receptor 1, hepatitis $\mathrm{C}$ virus, triglyceride, Huh7, replicon lipid accumulation appeared to increase after CB1 agonist treatment, while it decreased after CB1 antagonist treatment, although significant differences were not found compared to untreated cells. In Tet-On Core-2 cells, induction of HCV core protein expression did not affect CB1 expression or triglyceride accumulation. The results of this study in cultured cells suggest that HCV infection may activate the cannabinoid system and precede steatosis, but the core protein by itself may not have any effect on the cannabinoid system.

\section{Introduction}

Cannabinoids are hydrophobic fatty-acid-derived compounds with predominantly autocrine/paracrine effects acting via specific G-protein-coupled receptors (CB1 and CB2). Endocannabinoids, such as anandamide and 2-arachidonoylglycerol (2-AG), are not stored in cells and are synthesized on demand from lipid precursors in cellular membranes (1). They are released in response to specific stimuli and are rapidly degraded by fatty-acid amide hydrolase (FAAH) or monoacylglycerol lipase, following ligand binding and cellular uptake (2). Emerging evidence suggests the crucial role of the hepatic cannabinoid system, which appears to be mediated via activation of cannabinoid receptors in the pathogenesis of non-alcoholic fatty liver disease (NAFLD) and non-alcoholic steatohepatitis (NASH) (1-5). CB1 receptor stimulation contributes to liver steatosis progression and exerts profibrogenic and proinflammatory effects in the liver. Steatogenic agents such as a high-fat diet can up-regulate the activity of $\mathrm{CB} 1$ receptors via increasing the synthesis of endocannabinoids. In the NASH experimental model, hepatic anandamide levels increase following inhibition of its degradation by $\mathrm{FAAH}$, and $\mathrm{CB} 1$ receptor expression is strongly increased (6). CB1 receptors contribute to metabolic steatosis and the related insulin resistance, and can also be up-regulated by obesity (5-7). CB1 receptor activation results 
in up-regulation of the lipogenic transcription factor, sterol regulatory element-binding protein-1c (SREBP-1c), and its target enzymes, acetyl-CoA carboxylase-1 and fatty acid synthase (FASN), as well as concurrent down-regulation of carnitine palmitoyltransferase-1 (5-7). This leads to increased de novo fatty acid synthesis as well as decreased fatty acid oxidation. Evidence from $\mathrm{CB} 1$ receptor knockout mice or from mice with a selective deletion of $\mathrm{CB} 1$ receptors in hepatocytes indicated that over-activation of the cannabinoid system promotes obesity-associated fatty liver and insulin resistance (5-7). Clinically, rimonabant, a CB1 antagonist, reduces alanine aminotransferase levels in NAFLD patients (8). Rimonabant results in the reduction of obesity and hepatic steatosis in rodents (9-11). CB2 receptors may also be associated with fatty liver development (12). Although CB2 receptors are mostly found in immune system cells, high-fat diet appears to activate $\mathrm{CB} 2$ receptors in addition to $\mathrm{CB} 1$ receptors, and $\mathrm{CB} 2$ receptor activation appears to induce the protective role in the inflammatory and fibrogenic responses associated with chronic liver diseases $(13,14)$.

Hepatic steatosis and insulin resistance, which are rarely observed in autoimmune hepatitis and chronic hepatitis $\mathrm{B}$, are frequently present in patients with chronic hepatitis $\mathrm{C}(\mathrm{CH}-\mathrm{C})$. Fat accumulation promotes oxidative stress and inflammatory reactions. Also, a considerable number of studies have suggested that expression of various HCV proteins may lead to alterations in lipid metabolism and transport. In particular, the $\mathrm{HCV}$ core protein has been suggested to contribute to hepatic steatosis and induction of reactive oxygen species (ROS) (15-17). The HCV core protein interferes with the assembly of very low-density lipoprotein (VLDL) by reducing the level of microsomal triglyceride transfer protein (MTTP), and with the insulin signaling pathway. The HCV core protein causes steatosis via mitochondrial toxicity and ROS production. Because hepatocytes are involved in various metabolic pathways, HCV may interfere with lipid metabolism via one or several pathways. Although the details of the interaction between $\mathrm{HCV}$ and hepatic lipid metabolism remain unclear, the possibility that HCV influences cannabinoid processes, which are activated in NAFLD, has been suggested. Osei-Hyiaman et al revealed an increased CB1-dependent cannabinoid tone in the liver and hypothalamus of obese mice with fatty liver (6), suggesting that CB1 receptors promote liver steatogenesis via central orexigenic properties and peripheral lipogenic effects in hepatocytes, and that the cannabinoid system may play a significant role in the development of steatosis in $\mathrm{CH}-\mathrm{C}$ patients. Moreover, daily cannabis use appears to have a significant impact on the severity of steatosis and fibrosis progression in $\mathrm{CH}-\mathrm{C}$ patients (18). However, the precise mechanism and pathway by which $\mathrm{HCV}$ affects the hepatic cannabinoid system has not been thoroughly investigated. In this study, we focused on the association between the hepatic cannabinoid system and HCV gene expression, and examined the expression of $\mathrm{CB} 1$ receptors and triglyceride accumulation in the hepatic Huh7 cell line, expressing HCV genes.

\section{Materials and methods}

Cell lines. The human hepatoma (Huh7)-derived cell line, Tet-On Core-2, with tightly regulated core gene expression under the control of a tetracycline-regulated promoter was kindly gifted by the Department of Genetic Medicine and Regenerative Therapeutics, Tottori University. Tet-On Core-2 contains pTet-On Advanced (Clontech, Palo Alto, CA, USA), pTRE-Tight-Core (b1), in which the cDNA fragment encoding core segment of the HCV (genotype 1b) (19) was cloned into pTRE-Tight (Clontech), and pTK-Hyg (Clontech) for selection and doxycycline $(5 \mu \mathrm{g} / \mathrm{ml})$-induced expression of the core protein. The Huh7/Rep-Feo-1b cell line, which stably expresses the HCV Rep-Feo replicon, was kindly gifted by the Department of Gastroenterology and Hepatology, Tokyo Medical and Dental University. The HCV replicon plasmids, which contain the non-structural proteins (NS) 3, NS4, NS5A and NS5B, were derived from the HCV-N strain (genotype 1b). The construct expresses a chimeric reporter protein of firefly luciferase and neomycin phosphotransferase $(20,21)$. Cell lines were maintained in Dulbecco's modified Eagle's medium (Gibco-BRL, Grand Island, NY, USA), supplemented with $10 \%$ heat-inactivated fetal bovine serum (Gibco-BRL), $100 \mathrm{U} / \mathrm{ml}$ penicillin $\mathrm{G}$, and $0.1 \mathrm{mg} / \mathrm{ml}$ streptomycin (Gibco-BRL) in a humidified $37^{\circ} \mathrm{C} / 5 \% \mathrm{CO}_{2}$ incubator.

Oil Red $O$ staining. Cells were stained with Oil Red O to detect intracellular oil droplets. Cells were washed three times with phosphate buffered saline (PBS), fixed with $10 \%$ formaldehyde neutral buffer solution for $10 \mathrm{~min}$ and then stained with $3.3 \mathrm{mg} / \mathrm{ml}$ Oil Red $\mathrm{O}$ in $60 \%$ isopropanol for $30 \mathrm{~min}$. Cells were washed with PBS three times and observed under the microscope. Stained oil droplets were dissolved in $4 \%$ (v/v) Nonidet P-40 in isopropanol with gentle agitation for $5 \mathrm{~min}$. The OD of the supernatant was measured at $500 \mathrm{~nm}$.

Quantitative analysis of intracellular triglycerides. Triglycerides were measured by extracting lipids using the Folch method followed by triglyceride determination using the triglyceride E-test (Wako, Osaka, Japan).

Western blotting. Total cell lysate $(40 \mu \mathrm{g})$ was separated by SDS-PAGE and blotted onto a polyvinylidene fluoride membrane. The membrane was incubated with primary antibodies, followed by a peroxidase-labeled anti-IgG antibody, and visualized by chemiluminescence using the ECL Western blotting analysis system (Amersham Biosciences, Buckinghamshire, UK). The antibodies used were anti-HCVcore protein (AbD Serotec, Oxford, UK), anti-CB1 receptor (Affinity BioReagents, Golden, CO, USA), and anti- $\beta$-actin (Sigma, St. Louis, MO, USA).

Modification of CB1 receptor signaling and HCV expression. To stimulate or down-regulate the signaling pathway via the CB1 receptor, Huh7/Rep-Feo-1b cells were treated with an agonist (ACEA; Tocris Bioscience, Avonmouth, UK) or antagonist (AM251; Tocris Bioscience) for CB1 receptor. Each reagent was added to the cell medium at a concentration of $10 \mathrm{nM}$ and incubated for $48 \mathrm{~h}$. To down-regulate the expression of the HCV replicon, $100 \mathrm{U} / \mathrm{ml}$ IFNa (Dainippon Sumitomo Pharma, Tokyo, Japan) were added to the cell medium.

Real-time PCR. mRNA expression levels in Huh7/Rep-Feo-1b cells under IFN $\alpha$ treatment were analyzed using real-time 
Table I. Primer sets for real-time PCR.

\begin{tabular}{lll}
\hline Genes & \multicolumn{1}{c}{ Forward } & Reverse \\
\hline HCV & 5'-CCATGAATCACTCCCCTGTGAGGAACTA-3' & 5'-TCGCGGGGGCACGCCCAA-3' \\
LXR $\alpha$ & 5'-GCCGAGTTTGCCTTGCTCA-3' & 5'-TCCGGAGGCTCACCAGTTTC-3' \\
SREBP-1c & 5'-GGCTCCTGCCTACAGCTTCT-3' & 5'-CAGCCAGTGGATCACCACA-3' \\
FASN & 5'-GAACTCCTTGGCGGAAGAGA-3' & 5'-GGACCCCGTGGAATGTCA-3' \\
LDLR & 5'-CAACGGCTCAGACGAGCAAG-3' & 5'-AGTCACAGACGAACTGCCGAGA-3' \\
HMGR & 5'-GCCTGGCTCGAAACATCTGAA-3' & 5'-CTGACCTGGACTGGAAACGGATA-3' \\
ApoB & 5'-TCAAGAGTTACAGCAGATCCATCAA-3' & 5'-TCAGAATGGAAGTCCTTAAGAGCAA-3' \\
MTTP & 5'-AGCACCTCAGGACTGCGAAGA-3' & 5'-CAGAGGTGACAGCATCCACCA-3' \\
$\beta$-actin & 5'-TGGCACCCAGCACAATGAA-3' & 5'-CTAAGTCATAGTCCGCCTAGAAGCA-3' \\
\hline
\end{tabular}

LXR, liver X receptor; SREBP, sterol regulatory element-binding protein; FASN, fatty acid synthase; LDLR, LDL-receptor; HMGR, HMG-CoA reductase; ApoB, apolipoprotein B; MTTP, microsomal triglyceride transfer protein.

A

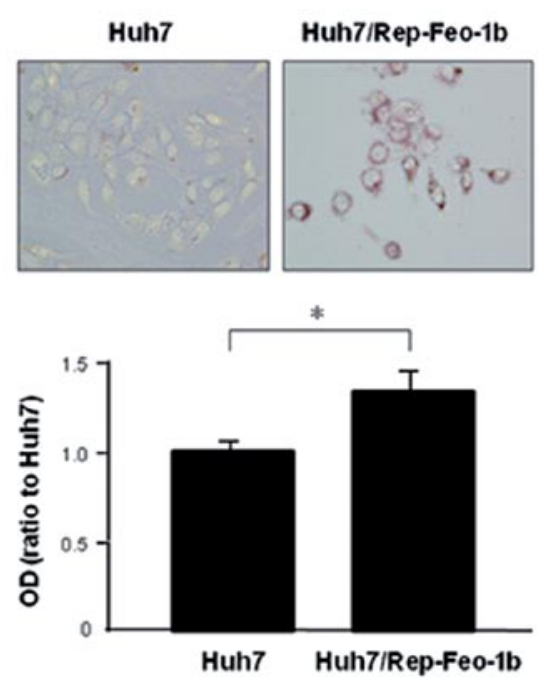

B

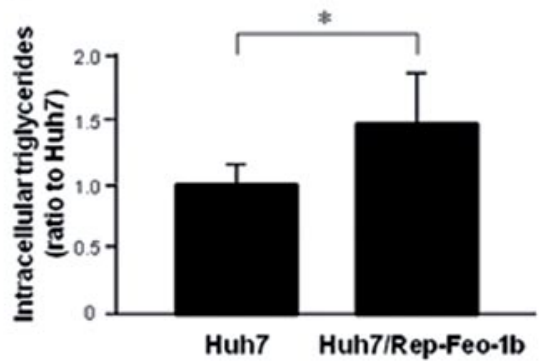

Figure 1. (A) Oil Red O staining images (upper panel; x20 magnification) and density of supernatant oil droplets (bar graph). (B) Triglyceride quantification assay; ${ }^{*} \mathrm{p}<0.05$.

RT-PCR and compared with untreated Huh7/Rep-Feo-1b cells. Total RNA was extracted with TRIzol reagent (Invitrogen, Carlsbad, CA, USA) and cDNA was synthesized from $1.0 \mu \mathrm{g}$ RNA using GeneAmp ${ }^{\mathrm{TM}}$ RNA PCR (Applied Biosystems, Branchburg, NJ, USA) with random hexamers. Real-time RT-PCR was performed using LightCycler-FastStart DNA Master SYBR-Green 1 (Roche, Basel, Switzerland) according to the manufacturer's instructions. The reaction mixture (20 $\mu \mathrm{l})$ contained LightCycler-FastStart DNA Master SYBRGreen $1,4 \mathrm{mM} \mathrm{MgCl}_{2}, 0.5 \mu \mathrm{M}$ upstream and downstream PCR primers, and $2 \mu \mathrm{l}$ first-strand cDNA as a template. To control for reaction variations, all PCR data were normalized against $\beta$-actin expression. The real-time RT-PCR primer sets in this study are listed in Table I.

Statistical analysis. Statistical analysis of CB1 receptor expression, Oil Red O incorporation and triglyceride accumulation was performed using the JMP software (SAS
Institute Inc., Cary, NC, USA). The results are expressed as the means $\pm \mathrm{SD}$. Continuous variables were compared using the Mann-Whitney $U$ test. Values of $p<0.05$ were considered statistically significant.

\section{Results}

Experiments on Huh7/Rep-Feo-1b cells. Accumulation of intracellular triglycerides was compared between Huh7 and Huh7/Rep-Feo-1b cells. Using Oil Red O staining (Fig. 1A) and the triglyceride quantification assay (Fig. 1B), we found that triglyceride levels were significantly higher in Huh7/ Rep-Feo-1b cells. Next, Huh7/Rep-Feo-1b cells were cultured with or without $100 \mathrm{U} / \mathrm{ml}$ IFN $\alpha$ for $48 \mathrm{~h}$ and HCV RNA replication was examined by real-time PCR. The expression levels of the HCV replicon were significantly suppressed by IFN $\alpha$ treatment (Fig. 2). The expression levels of lipid metabolism-associated genes were also evaluated by real-time 


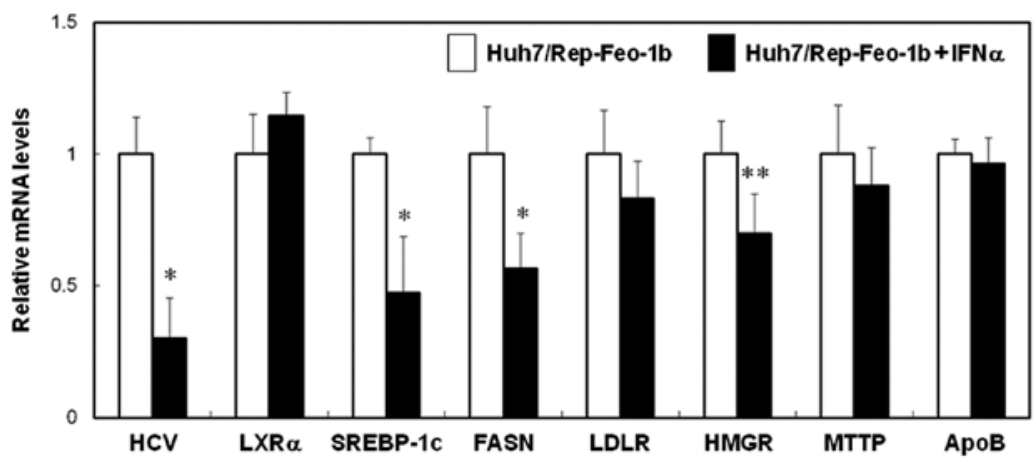

Figure 2. Quantitative real-time PCR for HCV and lipid metabolism-related genes. Expression levels in Huh7/Rep-Feo-lb cells after $48 \mathrm{~h}$ treatment with IFN $\alpha(100 \mathrm{U} / \mathrm{ml})$ were compared with untreated cells. LXR, liver X receptor; SREBP, sterol regulatory element-binding protein; FASN, fatty acid synthase; LDLR, LDL-receptor; HMGR, HMG-CoA reductase; MTTP, microsomal triglyceride transfer protein; ApoB, apolipoprotein B. ${ }^{*} \mathrm{p}<0.01,{ }^{* *} \mathrm{p}<0.05$.

A

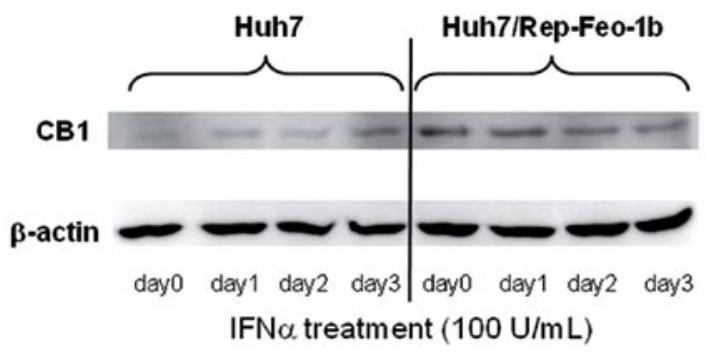

B

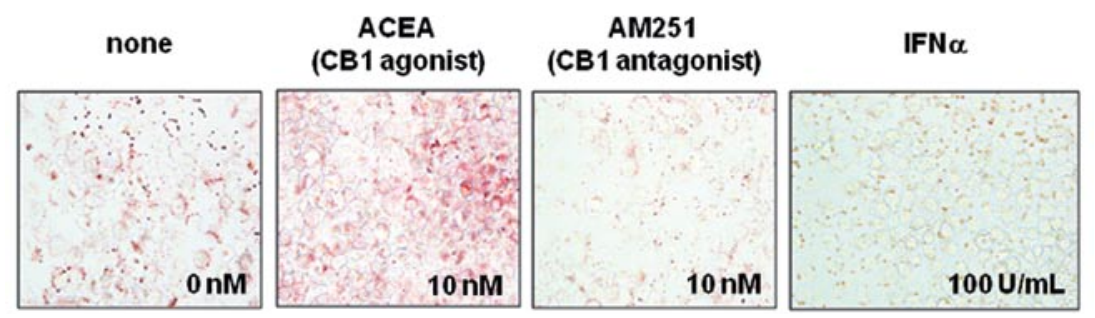

Figure 3. (A) Western blot analysis for the CB1 receptor. The expression levels in Huh7 and Huh7/Rep-Feo-1b cells were determined after treatment with $100 \mathrm{U} / \mathrm{ml}$ IFN $\alpha$ for $0,24,48$ and $72 \mathrm{~h}$. (B) Oil Red O staining (x10 magnification). Huh7/Rep-Feo-lb cells after $48 \mathrm{~h}$ incubation with IFN $(100 \mathrm{U} / \mathrm{ml}$ ), CB1 agonist $(10 \mathrm{nM})$ and $\mathrm{CB} 1$ antagonist $(10 \mathrm{nM})$ were compared with untreated cells (none).

A

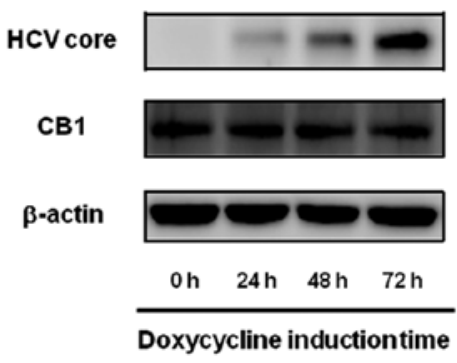

B

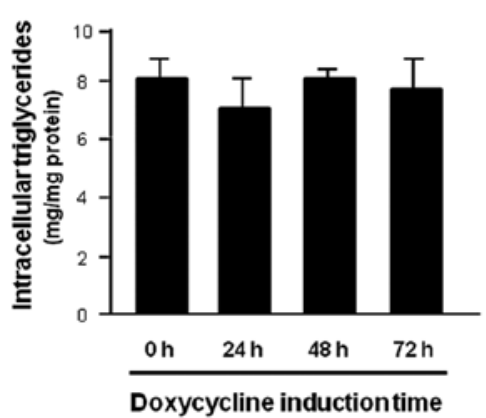

Figure 4. (A) Western blot analysis of the HCV core protein and the CB1 receptor. Expression levels in Tet-On Core-2 cells were analyzed before and after core protein induction with doxycycline $(5 \mu \mathrm{g} / \mathrm{ml})$. (B) Triglyceride quantification assay. No significant difference was found between any of the time points.

PCR. We found that in IFN $\alpha$-treated cells, SREBP-1c, FASN and HMG-CoA reductase (HMGR) were also significantly down-regulated (Fig. 2).

CB1 protein expression levels were examined by Western blot analysis in Huh7 and Huh7/Rep-Feo-lb cells treated with
$100 \mathrm{U} / \mathrm{ml} \mathrm{IFN} \alpha$ for $0,24,48$ and $72 \mathrm{~h}$. CB1 levels were noticeably higher in Huh7/Rep-Feo-1b cells compared with Huh7 cells. Furthermore, in Huh7/Rep-Feo-1b cells CB1 expression was suppressed by IFN $\alpha$ (Fig. 3A). In addition, we examined whether $\mathrm{CB} 1$ receptor signaling and $\mathrm{HCV}$ expression modify 
intracellular triglyceride accumulation. Triglyceride accumulation in Huh7/Rep-Feo-1b cells appeared to be induced by the CB1 agonist, ACEA, while it was decreased by the CB1 antagonist, AM251, and IFN $\alpha$ as judged by Oil Red O staining (Fig. 3B). However, when using the triglyceride quantification assay, the difference was not significant (data not shown).

Experiments on Tet-On Core-2 cells. Using Tet-On Core-2 cells (see Materials and methods) we examined how the $\mathrm{HCV}$ core protein modifies triglyceride accumulation and CB1 receptor expression. HCV core protein expression was clearly induced by $5 \mu \mathrm{g} / \mathrm{ml}$ doxycycline (Fig. 4A). However, doxycycline-induced core protein expression had no significant effect on triglyceride accumulation and CB1 receptor expression within $72 \mathrm{~h}$ (Fig. 4).

\section{Discussion}

The objective of this study was to examine the association between the expression of $\mathrm{HCV}$ genes and the activation of the cannabinoid system in vitro. As shown in Huh7/Rep-Feo-1b cells, CB1 receptor expression was up-regulated and triglyceride accumulation increased by stable expression of the HCV replicon, which includes the NS3, NS4, NS5A and NS5B genes (Fig. 1). When the replicon expression was suppressed by IFN $\alpha, \mathrm{CB} 1$ expression and triglyceride accumulation were attenuated, and the expression levels of the lipid metabolism-associated genes, SREBP-1c, FASN and HMGR, were concurrently down-regulated (Figs. 2 and 3). It is known that the expression of SREBP-1c and FASN, which stimulate hepatocellular fatty acid synthesis, is induced via CB1 receptor activation $(3,6)$. It is also commonly accepted that a major reason for steatosis in an $\mathrm{HCV}$-infected liver is down-regulation of MTTP expression by the core protein, followed by interference with VLDL assembly. However, MTTP levels did not change in Huh7/Rep-Feo-lb cells after IFN $\alpha$ treatment (Fig. 2). This may be because the HCV replicon does not contain the core gene. Therefore, it is likely that the hepatic cannabinoid system associates with triglyceride accumulation in Huh7/Rep-Feo-lb cells. Although the difference was not significant using the quantitative assay, the results shown in Fig. 3B imply that the CB1 agonist and antagonist modified the triglyceride accumulation in Huh7/ Rep-Feo-1b cells. However, the agonist or antagonist treatment did not change the expression levels of CB1 receptor, and the endocannabinoid, anandamide, could not be detected in the culture medium from Huh7/Rep-Feo-1b cells (data not shown). These results may suggest that HCV mainly affects the expression of $\mathrm{CB} 1$ receptor and that another endocannabinoid acts in Huh7/Rep-Feo-1b cells. On the other hand, the changes shown in the Huh7/Rep-Feo-1b cells did not occur in the Tet-On Core-2 cells under induction of core protein expression (Fig. 4), suggesting that the HCV core protein may not cause the activation of the cannabinoid system by itself.

The physiological expression of $\mathrm{CB} 1$ and $\mathrm{CB} 2$ receptors in adult liver hepatocytes is very low or even absent, and endocannabinoids are found in low levels in normal liver (22-25). Marked up-regulation of these receptors in cirrhotic human liver samples and increases in circulating levels of anandamide and 5-AG have been reported in liver cirrhosis and fibrosis (25-28). Therefore, in the liver of $\mathrm{CH}-\mathrm{C}$ as well as Huh7/Rep-Feo-1b cells, CB1 receptors may be up-regulated according to fibrotic change. However, in our previous realtime PCR study, CB1 receptor gene expression levels remained very low in liver samples from $\mathrm{CH}-\mathrm{C}$ patients as well as in normal individuals (unpublished data). Obviously, our in vitro data cannot reflect the occurrence in $\mathrm{CH}-\mathrm{C}$ patients, and other factors that do not exist in cell culture systems may affect the $\mathrm{CB} 1$ expression in vivo. Because $\mathrm{CB} 1$ and $\mathrm{CB} 2$ receptors are also up-regulated in acute liver damage, the degree and duration of inflammation may be an important factor in CB1 expression (or activation of the cannabinoid system) in vivo. Moreover, the existence of additional cannabinoid receptors other than CB1 and CB2, has been suggested (29). Other binding sites for endocannabinoids may exist depending on the circumstances of diseases, although they require further definition.

This in vitro study suggests that $\mathrm{HCV}$ proteins may activate the hepatic cannabinoid system, followed by lipid accumulation. However, the precise mechanism is still unclear. Which factors of HCV are essential for the activation of the hepatic cannabinoid system? How do these factors affect the system? Are additional stimulations, except for HCV infection, needed for significant activation of the cannabinoid system? Further studies are required to clarify these questions.

\section{References}

1. Parfieniuk A and Flislak R: Role of cannabinoids in chronic liver diseases. World J Gastroenterol 14: 6109-6114, 2008.

2. Mallat A and Lotersztajn S: Cannabinoid receptors as novel therapeutic targets for the management of non-alcoholic steatohepatitis. Diabetes Metab 34: 680-684, 2008.

3. Caraceni P, Domenicali M, Giannone F and Bernardi M: The role of the endocannabinoid system in liver diseases. Best Pract Res Clin Endocrinol Metab 23: 65-77, 2009.

4. Purohit V, Rapaka R and Shurtleff D: Role of cannabinoids in the development of fatty liver (steatosis). AAPS J 12: 233-237, 2010.

5. Kunos G and Osei-Hyiaman D: Endocannabinoids and liver disease. IV. Endocannabinoid involvement in obesity and hepatic steatosis. Am J Physiol Gastrointest Liver Physiol 294: G1101-G1104, 2008.

6. Osei-Hyiaman D, Depetrillo M, Pacher P, et al: Endocannabinoid activation at hepatic $\mathrm{CB}(1)$ receptors stimulates fatty acid synthesis and contributes to diet-induced obesity. J Clin Invest 115: 1298-1305, 2005.

7. Osei-Hyiaman D, Liu J, Zhou L, et al: Hepatic CB1 receptor is required for development of diet-induced steatosis, dyslipidemia, and insulin and leptin resistance in mice. J Clin Invest 118: 3160-3169, 2008

8. Van Gaal L, Pi-Sunyer X, Despres JP, McCarthy C and Scheen A: Efficacy and safety of rimonabant for improvement of multiple cardiometabolic risk factors in overweight/obese patients: pooled 1-year data from the Rimonabant in Obesity (RIO) program. Diabetes Care 31 (Suppl. 2): S229-S240, 2008.

9. Gary-Bobo M, Elachouri G, Gallas JF, et al: Rimonabant reduces obesity-associated hepatic steatosis and features of metabolic syndrome in obese Zucker fa/fa rats. Hepatology 46: 122-129, 2007.

10. Ravinet-Trillou C, Arnone M, Delgorge C, Gonalons N, Keane P, Maffrand JP and Soubrie P: Anti-obesity effect of SR141716, a CB1 receptor antagonist, in diet-induced obese mice. Am J Physiol Regul Integr Comp Physiol 284: R345-R353, 2003.

11. Kojima M, Kato N, Hirano D, Ochi T, Nii A, Shinjo K and Eda H: Selective CB1 cannabinoid receptor antagonist, SR141716A, attenuates liver injury induced by Concanavalin A. Hepatol Res 39: 408-414, 2009.

12. Mendez-Sanchez N, Zamora-Valdes D, Pichardo-Bahena R, et al: Endocannabinoid receptor CB2 in nonalcoholic fatty liver disease. Liver Int 27: 215-219, 2007. 
13. Lotersztajn S, Teixeira-Clerc F, Julien B, et al: CB2 receptors as new therapeutic targets for liver diseases. Br J Pharmacol 153: 286-289, 2008

14. Teixeria-Clerc F, Belot MP, Manin S, et al: Beneficial paracrine effects of cannabinoid receptor 2 on liver injury and regeneration. Hepatology 52: 1046-1059, 2010.

15. Yamaguchi A, Tazuma S, Nishioka T, Ohishi W, Hyogo H, Nomura $\mathrm{S}$ and Chayama K: Hepatitis $\mathrm{C}$ virus core protein modulates fatty acid metabolism and thereby causes lipid accumulation in the liver. Dig Dis Sci 50: 1361-1371, 2005.

16. Fukasawa M, Tanaka Y, Sato S, et al: Enhancement of de novo fatty acid biosynthesis in hepatic cell line Huh7 expressing hepatitis C virus core protein. Biol Pharm Bull 29: 1958-1961, 2006.

17. Pazienza V, Clément S, Pugnale P, Conzelman S, Foti M Mangia A and Negro F: The hepatitis $C$ virus core protein of genotypes $3 \mathrm{a}$ and $1 \mathrm{~b}$ downregulates insulin receptor substrate 1 through genotype-specific mechanisms. Hepatology 45: 1164-1171, 2007.

18. Hezode C, Zafrani ES, Roudot-Thoraval F, et al: Daily cannabis use: a novel risk factor of steatosis severity in patients with chronic hepatitis C. Gastroenterology 134: 432-439, 2008.

19. Marusawa H, Hijikata M, Chiba T and Shimotohno K: Hepatitis $\mathrm{C}$ virus core protein inhibits Fas- and tumor necrosis factor alpha-mediated apoptosis via NF- $\mathrm{kB}$ activation. J Virol 73: 4713-4720, 1999.

20. Yokota T, Sakamoto N, Enomoto N, et al: Inhibition of intracellular hepatitis $\mathrm{C}$ virus replication by synthetic and vector-derived small interfering RNAs. EMBO Rep 4: 602-608, 2003 .
21. Tanabe Y, Sakamoto N, Enomoto N, et al: Synergistic inhibition of intracellular hepatitis $C$ virus replication by combination of ribavirin and interferon- $\alpha$. J Infect Dis 189: 1129-1139, 2004.

22. Julien B, Grenard P, Teixeira-Clerc F, et al: Antifibrogenic role of the cannabinoid receptor CB2 in the liver. Gastroenterology 128: 742-755, 2005.

23. Teixeira-Clerc F, Julien B, Grenard P, et al: CB1 cannabinoid receptor antagonism: a new strategy for the treatment of liver fibrosis. Nat Med 12: 671-676, 2006.

24. Mallat A and Lotersztajin S: Endocannabinoids and liver disease. Am J Physiol 294: G9-G12, 2008.

25. Mallat A, Hezode C and Lotersztajn S: Environmental factors as disease accelerators during chronic hepatitis C. J Hepatol 48: 657-665, 2008

26. Bátkai S, Jarai Z, Wagner JA, et al: Endocannabinoids acting at vascular $\mathrm{CB} 1$ receptors mediate the vasodilated state in advanced liver cirrhosis. Nat Med 7: 827-832, 2001.

27. Fernandez-Rodriguez CM, Romero J, Petros TJ, et al: Circulating endogenous cannabinoid anandamide and portal, systemic and renal hemodynamics in cirrhosis. Liver Int 24: 477-483, 2004.

28. Siegmund SV, Qian T, de Minicis S, et al: The endocannabinoid 2-arachidonoyl glycerol induces death of hepatic stellate cells via mitochondrial reactive oxygen species. FASEB J 21: 2798-2806, 2007.

29. Pacher P, Bátkai S and Kunos G: The endocannabinoid system as an emerging target of pharmacotherapy. Pharmacol Rev 58: $389-462,2006$. 